\title{
ANALISIS KINERJA ALGORITMA CLUSTERING FUZZY TSUKAMOTO DENGAN FUZZY C-MEANS
}

\author{
Iin Parlina ${ }^{1}$, Prof.Herman Mawengkang ${ }^{2,}$ Dr.Syahril Efendi, S.Si, M.IT \\ Magister Teknik Informatika, Universitas Sumatera Utara \\ Jl. Universitas No.9A Kampus USU, Medan, Sumatera Utara-Indonesia \\ iinparlina34@gmail.com¹,hmawengkang@yahoo.com², syahrilefendi@yahoo.com ${ }^{3}$
}

\begin{abstract}
Efforts to evaluate employees in the work is to assess the performance of each employee. For it has been formulated assessment is based upon work objectives according to the position or job title, and by weighting against six indicators into three groups. The number of data values and indicators to be used will certainly lead to difficulties in implementation, not effective and less objective. Therefore we need a clustering process more optimal assessment. This study aims to analyze the performance of FCM algorithm implemented on employee performance evaluation PT. Bank Syariah Mandiri into 3 clusters. Some of the steps that must be performed before clustering, first performed pretreatment, namely data cleaning and data transformation for further clustering using the algorithm. The results of the calculations used to analyze the performance of the algorithm with FCM Tsukamoto. Compatibility calculation value data by Tsukamoto algorithm is pretty good and for the FCM algorithm is Very Good. FCM algorithm can be used in the assessment of grouping data based on the three criteria of assessment.
\end{abstract}

\begin{abstract}
Abstrak- Upaya untuk mengevaluasi pegawai dalam bekerja adalah dengan melakukan penilaian kinerja setiap pegawai. Untuk itu telah dirumuskan penilaian dilakukan berdasarkan sasaran kerja sesuai posisi ataupun jabatan dan dengan melakukan pembobotan terhadap 6 indikator ke dalam 3 kelompok. Banyaknya data nilai dan indikator yang harus digunakan tentunya akan menimbulkan kesulitan dalam pelaksanaannya, tidak efektif dan kurang obyektif. Oleh karena itu diperlukan proses clustering penilaian yang lebih optimal. Penelitian ini bertujuan untuk menganalisis kinerja algoritma FCM yang diimplementasikan pada penilaian kinerja pegawai PT. Bank Syariah Mandiri menjadi 3 cluster. Beberapa tahapan yang harus dilakukan sebelum dilakukan clustering, terlebih dahulu dilakukan prapengolahan yaitu data cleaning dan data transformation untuk selanjutnya dilakukan clustering menggunakan algoritma tersebut. Hasil perhitungan digunakan untuk menganalisa kinerja algoritma Tsukamoto dengan FCM. Kesesuaian hasil perhitungan data nilai dengan algoritma Tsukamoto adalah cukup Baik dan untuk algoritma FCM adalah Sangat Baik. Algoritma FCM dapat digunakan pada pengelompokan data penilaian berdasarkan ketiga kriteria penilaian.
\end{abstract}

Keywords-Clustering, Assessment, Fuzzy C-Means, Tsukamoto.

\section{PENDAHULUAN}

Fuzzy Clustering adalah salah satu teknik untuk menentukan cluster yang optimal dalam suatu ruang vector yang didasarkan pada bentuk normal euclidian untuk jarak antar vector. Fuzzy clustering sangat berguna bagi pemodelan fuzzy terutama dalam mengidentifikasi aturan-aturan fuzzy[1]. Pemilihan metode atau algoritma sangat berguna pada tujuan dan proses pengelompokan nilai secara keseluruhan. Fuzzy clustering model $C$-means mampu mengklaster data nilai terbaik. Hasil clustering ini dibuat untuk mengelompokkan nilai yang terbaik[2]. Salah satu proses Clustering ini adalah pengelompokan nilai pegawai dari beberapa atribut.

Pengelompokan nilai pegawai merupakan salah satu teknik untuk menentukan pegawai yang berprestasi berdasarkan sasaran kerja (Tugas Utama), Kompetensi dan Kepatuhan sebagai seorang pegawai[3]. Pengelompokan ini memberikan kemudahan dalam penilaian pegawai yang diinginkan. Pengelompokan nilai yang dilakukan akan memberi kemudahan bagi perusahaan untuk mencari pegawai yang masuk ke dalam kelas nilai terbaik.

Data Penilaian yang telah dikelompokkan akan tersusun rapi sesuai dengan kemiripan nilai tersebut. Nilai yang akan dikelompokkan dalam proses pengelompokan ini adalah nilai derajat keanggotaan yang menjadi ciri utama dalam penalaran dengan logika fuzzy tersebut[4].

Pengelompokan ini dikelompokkan menggunakan metode Fuzzy C-Means clustering dan Tsukamoto. Metode Tsukamoto merupakan teknik aturan yang membentuk suatu himpunan samar dengan fungsi keanggotaan yang menghasilkan nilai rata-rata himpunan. Sedangkan Konsep Fuzzy C-Means adalah pengklasteran data yang dilakukan yaitu dengan menentukan pusat cluster yang akan menandai lokasi rata-rata untuk tiap cluster. Pada kondisi awal pusat cluster masih belum akurat. Agar pusat cluster 
semakin akurat maka dibutuhkan perbaikan pusat cluster secara berulang-ulang hingga pusat cluster akan berada pada titik yang tepat. Setiap data akan memiliki derajat keanggotaan untuk tiap-tiap cluster [5]. Untuk memperoleh derajat keanggotaan yang tepat dibutuhkan perbaikan nilai keanggotaan sehingga data akan menempati cluster yang tepat.

Penilaian kinerja (Performance Appraisal) adalah proses mengevaluasi seberapa baik pegawai melakukan pekerjaan mereka jika dibandingkan dengan seperangkat standart, dan kemudian mengkomunikasikan informasi tersebut kepada pegawai. Penilaian kinerjajuga disebut pemeringkatan pegawai, evaluasi pegawai, tinjauan kerja, evaluasi kinerja dan penilaian hasil[6].

Pengelompokan ini dilakukan dengan menganalisa kinerja dari dua metode tersebut. Parameter yang digunakan untuk analisis kinerja metode tersebut adalah Tsukamoto dan C-Means. Tsukamoto menghitung nilai rata-rata dengan aturan rule yang menghasilkan pusat claster secara random[7]. Setelah itu dilakukan perhitungan secara berulang-ulang (iterasi) dalam satu klaster.

\section{METODOLOGI PENELITIAN}

Penelitian ini dilakukan di PT. Bank Syariah Mandiri kota Pematangsiantar Provinsi Sumatera Utara. dimulai Agustus 2016 sampai Januari 2017. Identifikasi data dilakukan untuk menganalisis kinerja algoritma model Tsukamoto untuk menghitung nilai dengan aturan rule dan inferensi sebagai bilangan random dan dengan model c-means untuk mengklastering nilai atau bilangan random dilakukan dengan cara berulang-ulang (tahap iterasi), lalu proses clustering nilai pegawai tersebut, dilakukan berdasarkan aturan dari algoritma c-means dengan menentukan parameter derajat keanggotaan untuk mencapai pusat cluster dan akan menghasilkan nilai matriks yang baru. Proses perhitungan pusat cluster akan berhenti saat nilai error telah ditemukan, dengan batas nilai $\xi=0,0001$ dan maksimal Iterasi $=50$, dan Cek kondisi Berhenti dengan Jika: $(|\mathrm{Pt}-\mathrm{Pt}-1|<\varepsilon)$ atau ( $\mathrm{t}>$ maxlter) maka berhenti atau $: \mathrm{t}=\mathrm{t}+1$, ulangi iterasi ke -5 .

Pengolahan dan analisis data dilakukan dengan perhitungan model Tsukamoto yang hasil fuzzifikasinya akan diekstrak kedalam model Fuzzy c-means sebagai data random berupa matriks U untuk dicluster dengan maksimal iterasi 30 .

\section{HASIL DAN PEMBAHASAN}

\section{A. Pengujian Algoritma C-Means}

Proses Pengelompokan data, yang dilakukan selanjutnya menggunakan hasil inferensi fuzzifikasi sebelumnya, dimana proses cluster dapat dilakukan dengan tahap pertahap yaitu:
1. Proses input data dilakukan untuk membangkitkan bilangan acak (random) sebagai data awal, seperti pada tabel 1 berikut:

TABEL I

DATA INPUT MODEL C-MEANS

\begin{tabular}{|c|c|c|c|c|c|}
\hline \multicolumn{5}{|c|}{$\begin{array}{l}\text { Nilai derajat keanggotaan } \\
\text { klaster } 1 \text { pada data pertama }\end{array}$} & \multirow{2}{*}{$\begin{array}{c}\text { Perhitungan pusat } \\
\text { cluster }(\mathrm{Vkj}) \text { pada } \\
\text { klaster-1 }\end{array}$} \\
\hline NO & $\begin{array}{r}\text { Data } \\
\text { ke-i }\end{array}$ & $\left(\mu \_i 1\right)$ & $\left(\mu_{-} i 1_{1}\right)^{\wedge} 2$ & $\begin{array}{l}\left(\mu_{-}(i .1)\right)^{\wedge} \\
2^{*} X_{-}(i .1)\end{array}$ & \\
\hline 1 & 78 & 0,8 & 0,64 & 49,92 & 0,000251606 \\
\hline 2 & 78 & 0,8 & 0,64 & 49,92 & 0,000251606 \\
\hline 3 & 78 & 0,8 & 0,64 & 49,92 & 0,000251606 \\
\hline 4 & 98 & 1,8 & 3,24 & 317,52 & 0,001600358 \\
\hline 5 & 78 & 0,8 & 0,64 & 49,92 & 0,000251606 \\
\hline 6 & 98 & 1,8 & 3,24 & 317,52 & 0,001600358 \\
\hline 7 & 78 & 0,8 & 0,64 & 49,92 & 0,000251606 \\
\hline 8 & 78 & 0,8 & 0,64 & 49,92 & 0,000251606 \\
\hline 9 & 78 & 0,8 & 0,64 & 49,92 & 0,000251606 \\
\hline 10 & 78 & 0,8 & 0,64 & 49,92 & 0,000251606 \\
\hline 11 & 78 & 0,8 & 0,64 & 49,92 & 0,000251606 \\
\hline 12 & 98 & 1,8 & 3,24 & 317,52 & 0,001600358 \\
\hline 13 & 98 & 1,8 & 3,24 & 317,52 & 0,001600358 \\
\hline 14 & 78 & 0,8 & 0,64 & 49,92 & 0,000251606 \\
\hline 15 & 58 & $-0,2$ & 0,04 & 2,32 & $1,16932 \mathrm{E}-05$ \\
\hline 16 & 78 & 0,8 & 0,64 & 49,92 & 0,000251606 \\
\hline 17 & 78 & 0,8 & 0,64 & 49,92 & 0,000251606 \\
\hline 18 & 78 & 0,8 & 0,64 & 49,92 & 0,000251606 \\
\hline 19 & 78 & 0,8 & 0,64 & 49,92 & 0,000251606 \\
\hline 20 & 58 & $-0,2$ & 0,04 & 2,32 & $1,16932 \mathrm{E}-05$ \\
\hline 21 & 98 & 1,8 & 3,24 & 317,52 & 0,001600358 \\
\hline 22 & 98 & 1,8 & 3,24 & 317,52 & 0,001600358 \\
\hline 23 & 98 & 1,8 & 3,24 & $\mathbf{3 1 7 , 5 2}$ & 0,001600358 \\
\hline 24 & 98 & 1,8 & 3,24 & 317,52 & 0,001600358 \\
\hline 25 & 58 & 58 & 3364 & 195112 & 0,983399662 \\
\hline 26 & 78 & 0,8 & 0,64 & 49,92 & 0,000251606 \\
\hline
\end{tabular}

Tabel diatas merupakan data input penilaian. Setelah kriteria dicocokkan maka diperoleh hasil nilai untuk mendapatkan bobot penilaian

2. Proses Cleaning Data Cleaning data adalah proses pengecekan data untuk penetapan dan pemulihan data yang hilang, dengan nilai-nilai tidak terdefinisi, sedangkan pemulihan data yang hilang adalah nilai dari suatu variabel yang tidak diketahui, sehingga nilai yang value tersebut tidak dapat digunakan.

TABEL II

PROSES PENENTUAN PARAMETER AWAL

\begin{tabular}{|l|c|}
\hline Parameter & Nilai \\
\hline Banyak klaster $(\mathrm{c})$ & 4 \\
\hline Pangkat $(\mathrm{w})$ & 2 \\
\hline Maksimum Iterasi & 50 \\
\hline Error $\varepsilon$ & 0,0001 \\
\hline Fungsi Objektif $\mathrm{P}_{0=0}$ & 0 \\
\hline Iterasi awal $\mathrm{t}=1$ & 1 \\
\hline
\end{tabular}

Setelah menetapkan nilai parameter awal, data siap untuk diklaster lalu dilakukan proses clustering menggunakan algoritma clustering fuzzy c-means, yaitu dengan melakukan tahaptahap sebagai berikut: 
a) Bangkitkan nilai acak

Nilai acak atau nilai random yaitu $\mu \mathrm{ik}, \mathrm{i}=26$; $\mathrm{k}=1$; sebagai elemen-elemen matriks partisi awal (U). Matriks partisi awal (u) dilakukan secara random dengan batas 0 hingga 1 , Matriks partisi awal yaitu sebagai berikut.

$$
\mathrm{U}=\left(\begin{array}{l}
0.8,0.8,0.8 \\
0.8,0.8,0.2 \\
0.8,1.8,1.8 \\
1.8 .1 .8 .1 .8 \\
0.8 .0 .8 .1 .8 \\
1.8 .0 .2 .1 .8 \\
0.8 .0 .8 .58 \\
0.8,0.8,0.8
\end{array}\right)
$$

b) Pengujian pusat cluster

Pengujian nilai pusat cluster dihitung dengan menggunakan persamaan berikut:

$$
\mathrm{V}_{\mathrm{kj}}=\frac{\sum_{i=1}^{n}\left(\mu_{i j}\right)^{w} * X_{i j}}{\sum_{i=1}^{n}\left(\mu_{i k}\right)^{w}}
$$

Dimana : $V_{\mathrm{kj}}$ adalah titik pusat tiap cluster, jumlah $\mathrm{V}_{\mathrm{kj}}$ tergantung dari berapa cluster yang akan dibentuk dan $\mathrm{n}$ ialah jumlah pegawai.

c) Menghitung fungsi obyektif

Menghitung proses perubahan matriks pada iterasi pertama dihitung dengan persamaan berikut:

$$
P_{(t)}=\sum_{i=1}^{n} \sum_{k=1}^{c}\left(\left\lceil\sum_{j=1}^{m}\left(X_{i j}-V_{k j}\right)^{2}\right\rceil\right)\left(\mu_{i k}\right)^{w}
$$

d) Menghitung Perubahan Matrisk iterasi 1 Menghitung proses perubahan matriks pada iterasi pertama dihitung dengan persamaan berikut :

$$
\mu_{i k(t)}=\frac{\left[\sum_{j=1}^{m}\left(X_{i j}-V_{k j}\right)^{2}\right]^{\frac{-1}{w-}}}{\sum_{k 1=}^{c}\left[\sum_{j=1}^{m}\left(X_{i j}-V_{k j}\right)^{2}\right]^{\frac{-1}{w-}}}
$$

Selanjutnya melakukan pengecekan kondisi berhenti. Karena $\left|\mathrm{P}_{1}-\mathrm{P}_{0}\right|=|58,36145429-0|=$ $58,36145429>\xi\left(10^{-5}\right)$, dan iterasi $=1<$ MaxItr $(=20)$, maka dilanjutkan ke iterasi ke-2 (t=2). Pada iterasi ke-2, diperoleh kembali pusat cluster sebagai berikut:

$$
\mathrm{V}=[73,28623619]
$$

Fungsi objektif pada iterasi ke-2 $\mathrm{P}_{2}$ diperoleh $\mathrm{P}_{2}=73,28623619$. selanjutnya matriks partisi $\mathrm{U}$ setelah diperbaiki diperoleh kondisi berhenti. Karena $\left|\mathrm{P}_{2} \mathrm{P}_{1 \mid}=\right| 73,28623619$ $58,36145429 \mid=14,9247819>\xi\left(10^{-5}\right)$, dan iterasi $=2<$ MaxIter $(=30)$, maka proses dilanjutkan ke iterasi ke-3 $(\mathrm{t}=3)$. Demikian seterusnya, hingga : $\left|\mathrm{P}_{\mathrm{t}}-\mathrm{P}_{\mathrm{t}-1}\right|<\xi$ atau $\mathrm{t}>$ MaxIter. Untuk contoh kasus ini, proses akan berhenti setelah iterasi ke-24 dengan pusat cluster sebagai berikut:

$$
\mathrm{V}=[78,00002597]
$$

TABEL III

HASIL PERUBAHAN MATRIKS PADA ITERASI TERAKHIR

\begin{tabular}{|r|r|r|r|r|}
\hline No & \multicolumn{1}{|c|}{ Miu21 } & \multicolumn{1}{c|}{ Miu22 } & \multicolumn{1}{c|}{ Miu23 } & \multicolumn{1}{c|}{ Miu24 } \\
\hline 53 & 0,0019111 & $-0,000160182$ & $-0,000160182$ & $-0,000160182$ \\
\hline 54 & 0,103426163 & $-0,000160182$ & $-0,000160182$ & $-0,000160182$ \\
\hline 55 & 0,103426163 & $-0,000160182$ & $-0,000160182$ & $-0,000160182$ \\
\hline 56 & 0,00359079 & 0,003879745 & 0,003879745 & 0,003879745 \\
\hline 57 & 0,103426163 & $-0,000160182$ & $-0,000160182$ & $-0,000160182$ \\
\hline 58 & 0,00359079 & 0,003879745 & 0,003879745 & 0,003879745 \\
\hline 59 & 0,103426163 & $-0,000160182$ & $-0,000160182$ & $-0,000160182$ \\
\hline 60 & 0,103426163 & $-0,000160182$ & $-0,000160182$ & $-0,000160182$ \\
\hline 61 & 0,103426163 & $-0,000160182$ & $-0,000160182$ & $-0,000160182$ \\
\hline 62 & 0,103426163 & $-0,000160182$ & $-0,000160182$ & $-0,000160182$ \\
\hline 63 & 0,103426163 & $-0,000160182$ & $-0,000160182$ & $-0,000160182$ \\
\hline 64 & 0,00359079 & 0,003879745 & 0,003879745 & 0,003879745 \\
\hline 65 & 0,00359079 & 0,003879745 & 0,003879745 & 0,003879745 \\
\hline 66 & 0,103426163 & $-0,000160182$ & $-0,000160182$ & $-0,000160182$ \\
\hline 67 & 0,00184827 & 0,00386544 & 0,00386544 & 0,00386544 \\
\hline 68 & 0,103426163 & $-0,000160182$ & $-0,000160182$ & $-0,000160182$ \\
\hline 69 & 0,103426163 & $-0,000160182$ & $-0,000160182$ & $-0,000160182$ \\
\hline 70 & 0,103426163 & $-0,000160182$ & $-0,000160182$ & $-0,000160182$ \\
\hline 71 & 0,103426163 & $-0,000160182$ & $-0,000160182$ & $-0,000160182$ \\
\hline 72 & 0,00184827 & 0,00386544 & 0,00386544 & 0,00386544 \\
\hline 73 & 0,00359079 & 0,003879745 & 0,003879745 & 0,003879745 \\
\hline 74 & 0,00359079 & 0,003879745 & 0,003879745 & 0,003879745 \\
\hline 75 & 0,00359079 & 0,003879745 & 0,003879745 & 0,003879745 \\
\hline 76 & 0,00359079 & 0,003879745 & 0,003879745 & 0,003879745 \\
\hline 77 & 0,00184827 & 0,00386544 & 0,00386544 & 0,00386544 \\
\hline 78 & 0,103426163 & $-0,000160182$ & $-0,000160182$ & $-0,000160182$ \\
\hline & & & & \\
\hline
\end{tabular}

Dari matriks partisi $U$ tersebut dapat diperoleh informasi mengenaii kecendrungan suatu nilai umtuk masuk ke kelompok (cluster) yang mana. Suatu nilai derajat keanggotaan tertentu untuk menjadi anggota suatu kelompok. Derajat keanggotaan terbesar menunjukkan kecendrungan tertinggi suatu nilai keanggotaan tiap pegawai. 
TABEL IV

HASIL PROSES PERHITUNGAN DERAJAT KEANGGOTAAN TIAP DATA PADA SETIAP CLUSTER

\begin{tabular}{|c|c|c|c|c|c|c|c|c|c|c|c|c|}
\hline \multirow{2}{*}{ No } & \multicolumn{6}{|c|}{ Derajat Keanggotaan Data Pada Cluster } & \multicolumn{6}{|c|}{$\begin{array}{l}\text { Derajat Kcanggotaan } \\
\text { Data Pada Cluster }\end{array}$} \\
\hline & 1 & 2 & 3 & 4 & 5 & 6 & 1 & 2 & 3 & 4 & 5 & 6 \\
\hline 53 & 0,0013 & 0,0459 & 0,0018 & 0,0039 & 0,0039 & 0,0039 & & & & & & $*$ \\
\hline 54 & 0,0013 & 0,0459 & 0,0018 & 0,0039 & 0,0039 & 0,0039 & & & & & & * \\
\hline 55 & 0.0013 & 0,0459 & 0,0018 & 0,0039 & 0,0039 & 0,0039 & & & & & * & \\
\hline 56 & 0,1156 & 0,0279 & 0,0019 & $-0,0002$ & $-0,0002$ & $-0,0002$ & & & & & $*$ & \\
\hline 57 & 0,1156 & 0,0459 & 0,0036 & 0,0039 & 0,0039 & 0,0039 & & & & & $*$ & \\
\hline 58 & 0,1156 & 0,0279 & 0,0036 & 0,0039 & 0,0039 & 0,0039 & & & & & * & \\
\hline 59 & 0,1156 & 0,0459 & 0,0036 & 0,0039 & 0,0039 & 0,0039 & & & & & $*$ & \\
\hline 60 & 0,1156 & 0,0459 & 0,0036 & 0,0039 & 0,0039 & 0,0039 & & & & & $*$ & \\
\hline 61 & 0,1156 & 0,0459 & 0,0036 & 0,0039 & 0,0039 & 0,0039 & & & & & * & \\
\hline 62 & 0,1156 & 0,0459 & 0,0036 & 0,0039 & 0,0039 & 0,0039 & & & & & * & \\
\hline 63 & 0,1156 & 0,0459 & 0,0036 & 0,0039 & 0,0039 & 0,0039 & & & & & $*$ & \\
\hline 64 & 0,1156 & 0,0279 & 0,0036 & 0,0039 & 0,0039 & 0,0039 & & & & " & & \\
\hline 65 & 0,1156 & 0,0279 & 0,1034 & $-0,0002$ & $-0,0002$ & $-0,0002$ & & & * & & & \\
\hline 66 & 0,1156 & 0,0459 & 0,1034 & $-0,0002$ & $-0,0002$ & $-0,0002$ & & & & " & & \\
\hline 67 & 0,1156 & 0,0017 & 0,1034 & $-0,0002$ & $-0,0002$ & $-0,0002$ & & & & * & & \\
\hline 68 & 0,1156 & 0,0459 & 0,1034 & $-0,0002$ & $-0,0002$ & $-0,0002$ & & & $*$ & & & \\
\hline 69 & 0,1156 & 0,0459 & 0,1034 & $-0,0002$ & $-0,0002$ & $-0,0002$ & & & * & & & \\
\hline 70 & 0,1156 & 0,0459 & 0,1034 & $-0,0002$ & $-0,0002$ & $-0,0002$ & $*$ & & & & & \\
\hline 71 & 0,7517 & 0,0459 & 0,1034 & $-0,0002$ & $-0,0002$ & $-0,0002$ & $*$ & & & & & \\
\hline 72 & 0,7517 & 0,0017 & 0,1034 & $-0,0002$ & $-0,0002$ & $-0,0002$ & $*$ & & & & & \\
\hline 73 & 0,7517 & 0,0279 & 0,1034 & $-0,0002$ & $-0,0002$ & $-0,0002$ & $*$ & & & & & \\
\hline 74 & 0.7517 & 0,0279 & 0,1034 & $-0,0002$ & $-0,0002$ & $-0,0002$ & $*$ & & & & & \\
\hline 75 & 0,7517 & 0,0279 & 0.1034 & $-0,0002$ & $-0,0002$ & $-0,0002$ & $*$ & & & & & \\
\hline 76 & 0,7517 & 0,0279 & 0,1034 & $-0,0002$ & $-0,0002$ & $-0,0002$ & $*$ & & & & & \\
\hline 77 & 0,7517 & 0,0017 & 0,1034 & $-0,0002$ & $-0,0002$ & $-0,0002$ & $*$ & & & & & \\
\hline 78 & 0,7517 & 0,0459 & 0,1034 & $-0,0002$ & $-0,0002$ & $-0,0002$ & & * & & & & \\
\hline
\end{tabular}

Dengan mengurutkan pusat cluster dapat menampilkan bahwa cluster ke-3 merupakan pusat cluster terbesar (cluster yang akan mendapat nilai A) dan selanjutnya yaitu cluster ke-4 (nilai B), dan seterusnya. Berikut ini merupakan nilai yang diperoleh setelah data dikelompokkan dengan FCM (Fuzzy CMeans).

TABEL V

HASIL PENGELOMPOKAN NILAI

\begin{tabular}{|c|c|c|c|c|}
\hline \multirow[t]{2}{*}{ No } & \multirow[t]{2}{*}{ NIP } & \multicolumn{3}{|c|}{$\begin{array}{c}\text { Derajat Keanggotaan } \\
\text { Dala Pauda Clus er }\end{array}$} \\
\hline & & Cluster & Total Nilai & Nilai \\
\hline 1 & 088473712 & 6 & 0,12 & TB \\
\hline 2 & 077573169 & 6 & 0,12 & TB \\
\hline 3 & 108274614 & 5 & 0,21 & $\mathrm{HB}$ \\
\hline 4 & 098574118 & 5 & 0,32 & B- \\
\hline 5 & 159314841 & 5 & 0,34 & B- \\
\hline 6 & 108977280 & 5 & 0,34 & B- \\
\hline 7 & 128511317 & 5 & 0,35 & B- \\
\hline 8 & 058172499 & 5 & 0,35 & B- \\
\hline 9 & 108774532 & 5 & 0,35 & B- \\
\hline 10 & 128911316 & 5 & 0,35 & B- \\
\hline 11 & 077873149 & 5 & 0,34 & B- \\
\hline 12 & 128711931 & 4 & 0,41 & B- \\
\hline 13 & 048071877 & 3 & 0,51 & $\mathrm{~B}^{+}$ \\
\hline 14 & 128412388 & 4 & 0,48 & B- \\
\hline 15 & 108577015 & 4 & 0,48 & B- \\
\hline 16 & 108377276 & 3 & 0.53 & $\mathrm{~B}^{+}$ \\
\hline 17 & 108277016 & 3 & 0,53 & $\mathrm{~B}^{+}$ \\
\hline 18 & 118579191 & 1 & 1,16 & SB \\
\hline 19 & 128810764 & 1 & 1,76 & SB \\
\hline 20 & 088.373321 & 1 & 1,74 & $\mathrm{SB}$ \\
\hline 21 & 128910732 & 1 & 1,76 & SB \\
\hline 22 & 118911290 & 1 & 1,76 & SB \\
\hline 23 & 088373322 & 1 & 1,76 & SB \\
\hline 24 & 058172487 & 1 & 1,74 & SB \\
\hline 25 & 118479197 & 1 & 1,76 & SB \\
\hline 26 & 108774744 & 2 & 0,90 & LB \\
\hline
\end{tabular}

Berdasarkan tabel diatas dapat diketahui bahwa cluster 1 memiliki matriks input (total nilai) antara 0,9 sampai 1,76. Cluster 2 memiliki matriks input (total nilai) antara 0,8 sampai 0,9 . Cluster 3 memiliki matriks input (total nilai) antara 0,7 sampai 0,8 . Cluster ke 4 memiliki matriks input (total nilai) 0,6 sampai 0,7. Cluster 5 memiliki matriks input (total nilai) 0,5 sampai 0,4. Cluster 6 memiliki matriks input (total nilai) 0,4 sampai 0,1 .

Berdasarkan pengujian yang telah dilakukan dapat diambil kesimpulan, yaitu sebagai berikut:

1. Pengujian Fuzzy C-Means telah dilakukan sebanyak 23 kali pengujian (iterasi) membeikan hasil bahwa sistem mampu mengklasifikasikan nilai pegawai dengan hasil nilai akhir diurutkan berdasarkan pusat cluster. Akan tetapi sistem tidak mampu mengelompokkan pegawai ketika data dikelompokkan merupakan data yang sama (tidak memiliki rentang nilai)

2. Pengujian berdasarkan metode Tsukamoto memberikan hasil keluaran sistem tidak sesuai yang diharapkan yaitu dapat memberikan kelompok pegawai yang memiliki nilai sesuai dengan jumlah kelompok yang diharapkan.

3. Pengujian berdasarkan model Tsukamoto dan C-Means, dari segi implementasi dan segi algoritma, sistem ini sudah dikatakan layak digunakan dalam pengklasifikasian pegawai berdasarkan kinerja.

\section{HASIL DAN PEMBAHASAN}

Kesimpulan yang dapat diambil dari hasil clustering pada data penilaian menggunakan metode fuzzy c-means antara lain :

1. Fuzzy C-Means tidak mengelompokkan data jika data memiliki total nilai yang sama. Dengan demikian Fuzzy C-Means hanya mampu mengelompokkan data yang total nilainya memiliki rentang nilai.

2. Pada Fuzzy C-Means, pengelompokan data dapat menghasilkan kelompok pegawai yang standart penilaiannya bersifat dinamis.

3. Hasil klasifikasi berdasarkan kinerja Tsukamoto dan FCM telah berhasil dibangun untuk menghasilkan kelompok sesuai dengan jumlah kelompok yang diinginkan.

\section{REFERENCE}

[1] Kusumadewi, S.and Purnomo, H. 2010. Aplikasi Logika Fuzzy Untuk Pendukung Keputusan. Graha Ilmu. Yogyakarta.

[2] Hamzah, Amir, et al. "Studi kinerja fungsi-fungsi jarak dan similaritas dalam clustering dokumen teks berbahasa indonesia." Seminar Nasional Informatika (SEMNASIF). Vol. 1. No. 1. 2015 
[3] Koesmono, H. Teman. "Pengaruh budaya organisasi terhadap motivasi dan kepuasan kerja serta kinerja karyawan pada sub sektor industri pengolahan kayu skala menengah di jawa timur." Jurnal Manajemen dan Kewirausahaan (Journal of Management and Entrepreneurship) 7.2 (2006): pp-171.

[4] Suprihanto. J. (2006) Penilaian Kinerja dan Pengembangan karyawan. Yogyakarta: BPFE UGM.

[5] Luthfi, Emha Taufiq. "Fuzzy C-Means untuk Clustering Data (studi kasus: data performance mengajar dosen)." Prosiding Seminar Nasional Teknologi, Yogyakarta. 2007.

[6] A Wisnujati, Inu. "Pembentukan sistem inferensi fuzzy mamdani dengan fuzzy C-means untuk data mahasiswa baru IPB tahun 2000-2004." (2006).

[7] Kaswidjanti, Wilis. "Implementasi Fuzzy Inference System Metode Tsukamoto Pada Pengambilan Keputusan Pemberian Kredit Pemilikan Rumah." Telematika 10.2 (2014). 